\title{
ARE COMICS EFFECTIVE MATERIALS FOR TEACHING ELLS? A LITERATURE REVIEW ON GRAPHIC MEDIA FOR L2 INSTRUCTION
}

\author{
Erika Edith Clark \\ Teachers College, Columbia University, The United States, eec2147@tc.columbia.edu
}

\begin{abstract}
In spite of the arguments teachers, parents, librarians, and critics have raised against students reading comics, research has demonstrated the effective use of comics in the classroom. This paper is a review of the literature that justifies how comics have been used to spark student motivation, heighten vocabulary acquisition, enhance multiple literacies, and improve multimodal skills during the learning process. These multimodal skills are essential for reading comics, since readers are required to make meaning of the visual, audio, and narration features of a comic. Even though the idea of using comics in the general education classroom is becoming more accepted, these discoveries still do not answer a vital question in the field of English Language Learning Pedagogy, which is "Are comics effective materials to use with English Language Learners (ELLs)?" This question helps professionals and researchers further explore the legitimacy of using comics as a tool for teaching and improving language skills. Using James W. Brown's (1977) research as a theoretical foundation, experiences that language learners encounter while reading comics in the target foreign language are clarified. In addition, further language pedagogical practices, based on fieldwork and teaching experience with ELLs in public grade schools and universities in New York City and abroad, are proposed at the conclusion of this literature review. Such proposed practices are instructional practices from the following locations: New York, United States; Tsinghua University in Beijing, China; Chon Buri, Thailand; Traduc Inc. in Santiago, Chile; and Puerto Bolivar, Ecuador.
\end{abstract}

Keywords: ENL, EFL, comics, motivation, vocabulary, multimodal texts

\section{STAKING OUT A CONTROVERSY ABOUT CHILDREN READING COMICS}

During fieldwork in a third grade dual English and Spanish language classroom in New York City, several newly arrived and long term English Language Learners (ELLs) were observed. Scrambling through shelves of the school library on a typical Wednesday, the class was searching for books they could read during independent reading time. One ELL had chosen a picture book Knuffle Bunny by Mo Williams, while another ELL selected the graphic novel Bone by Jeff Smith. When the teacher spotted the reading selections by these students, she immediately informed them to find another book: "preferably a chapter book," she added. It seemed as though this teacher did not take the graphic novel genre as appropriate reading material for her students, since comics and graphic novels included more visuals and less text when compared to the 
traditional chapter book.

The idea that comics and graphic novels were not "real" or "preferable" reading materials through the eyes of many teachers is a reoccurring historical argument. Psychiatrist Fredric Wertham was one of the first wellknown and published critics who argued against children reading comic books. Wertham's views unfortunately persuaded many parents and teachers to view comics as inappropriate reading material. Wertham argued that the violent imagery found in comics would negatively influence children's development by causing them to slowly demonstrate similar behaviors in their everyday routines (Wertham, 1954).

In addition, claims were made that when children were reading comics, they were not truly reading the text. Instead, they were simply looking at the images and occasionally acquiring new vocabulary words. According to Wertham's research during that time, these comic book fanatics also tended to be statistically the same percentage of youth who had reading difficulties in school. Thus, by observing low-performing students, Wertham argued that students spent the majority of their time pretending to read. They were simply focusing their attention on the images and not problem solving the words in the dialogue or narrative (Wertham, 1954).

\section{Observations of L2 Comic Instruction}

At an international high school in The Bronx, New York, the instructor had ELLs study and identify literary elements from the graphic novel Maus by Art Spiegelman. Then students were instructed to compare the literary elements from Maus with elements in the traditional non-comic style text about the holocaust titled The Boy in Striped Pajamas. In this English as a New Language (ENL) context, a graphic novel was used to initially build background knowledge about a historical topic, introduce content specific vocabulary, and spark the students' interest in the very beginning of an integrated Global Studies and English Language Arts (ELA) unit plan. Then the non-graphic text was used to help students develop greater comprehension on the subject and further analyze events that took place during that time period. Finally, students were able to appreciate the format of both texts, since they were taught to compare and contrast literary elements from both mediums. Thus, one medium was not used as a reading preference over the other, but both mediums were incorporated effectively to improve ENL instruction and accommodate students' diverse linguistic and academic needs.

\section{Teaching Experience in the EFL Context}

Considering the abundance of current testimonies from teachers with general education students, I questioned the legitimacy of comic instruction with ELLs. Attempting to complete pilot activities with a group of EFL students, Fiske's (1999), Deasy's (2002), Glasgow's (2002), and Bitz' (2004; 2009), were studies used as a point of reference and guidance. The purpose of using daily comic strips in English instruction, but in a foreign language context was to observe the potential comics could have on students' motivation to read and improve in the target language. In addition, studies like Samuels (1967), Singer et al (1974), and Horst and Meara's (1999) were referenced to justify observations and comparisons made of vocabulary acquisition between a group introduced to comic instruction as opposed to a group without comic-filled lessons and activities. In this case study, a native Dutch speaker learning English was given a comic book in the L2 to read for an eight-week duration. Researchers hypothesized that the images accompanied with the text would increase the reader's vocabulary in the foreign language. Results demonstrated that the reader progressed from a baseline of 82 words to acquiring 223 words by the end of the study. Therefore, I hypothesized that the usage of comic strips from the local newspaper in the EFL classroom would build motivation and vocabulary acquisition in the target language, as opposed to using traditional singular-layered texts.

As a full-time EFL teacher at a public school on the coast of Ecuador, I taught English instruction to 244 students, grades fifth, sixth, and seventh (two classes for each grade level). Since the seventh graders' reading levels were more advanced than the younger students, comic activities were instructed to one of the two seventh grade classes. Similar to the Horst and Meara (1999) study, students were given a pretest before the start of the unit plan on emotions. After instruction, both groups were given a post-test, which calculated the intake and recall of the target vocabulary words. To observe learning differences between learning a foreign language with continuous visuals as opposed to learning a foreign language without continuous visuals, one class was designated as the comic group, whereas the other class was the noncomic group. Therefore, both groups were given the same instruction and language objectives, but one group was expected to demonstrate their learning of the target vocabulary using comics instead of traditional 
methods (e.g., writing target vocabulary in a single-layered story).

As an attempt to explore student motivation, comic curriculum, and English vocabulary acquisition, observations of the students' behavior and reactions to the comics were impressionable. Aside from classwork and assessments that were gathered, the students' participation from the comic group was vastly different from the group that did not complete activities with comic strips. Coincidently, the majority of students were familiar with reading comics in their first language, like Coné by Chilean author Pepo. Even though students were accustomed to reading, writing, speaking, and listening during kinesthetic activities and songs during other English lessons, comics brought a higher element of motivation to read in the L2 in the classroom.

Even during experiences as a foreign language learner, I vaguely remember instructors using similar graphic media to motivate learning. Learning to read, write and converse in an L2 was not a simple task. After reflecting on personal experiences, teaching, and observations, comics and graphic novels served several purposes in my foreign language and second language classrooms. Therefore, literature in which researchers have justified how comics were used to spark student motivation will be reviewed. Other researchers have either looked at vocabulary acquisition from students reading comics, or researchers have analyzed comics to further comment on the appropriateness and difficulty of the vocabulary for students. Lastly, studies on student improvement in multiple literacies and multimodal cognitive function from reading comics will also be explored. These focuses within the literature will help teachers and even those who have oppositional viewpoints about comics answer the question, "Are graphic novels effective materials to use with ELLs?"

\section{REVIEW OF LITERATURE}

\subsection{Comics versus Graphic Literature}

In this paper, comics are defined as a literary medium, including four consistent elements to help readers comprehend the text, develop mental voices to represent the characters, analyze the dialogue, and visualize other literary elements in a story. Authors and comic creators display these elements by using sequential art (Eisner, 1996; McCloud, 1993), consistent dialogue, and a text that usually consists of basic vocabulary. Graphic novels, similarly, were defined as a text that consisted of the same three aforementioned story and text features, yet included a lengthier storyline and more literary elements, which gave the reader a betterdeveloped literary foundation (Gorman, 2003). Hence, graphic novels were accepted as a type of novel and were not a dependent story within a number of magazine-style issues like comic books. In contrast to graphic novels, traditional comics books were written for entertainment and consisted of topics that were popular amongst a given culture, such as those created by Dark Horse and Marvel Comics or popular titles like Peanuts, Archie Comics, and more (Frey \& Fisher, 2008). Regardless of this difference between the two, comics (i.e., comic books, magazines, or strips) and graphic novels will be referenced interchangeably throughout this paper, since they are two forms of graphic mediums under the same umbrella, Comics.

\subsection{Motivation and Comics}

Motivation was one of the leading reasons why children and adolescents were more likely to pick up a comic book than traditional reading materials. Jeff Smith founded his motivation to learn how to read at young age from the panels in comics. While growing up, his father would read to him the popular newspaper strip Peanuts. Smith found the comic strip so intriguing that he could not wait until he learned how to read them independently (Frey \& Fisher, 2008). Little did Smith know, he not only felt compelled to learn how to read these strips, but he would also become the author of the well-known graphic novel series Bone and an inspiration to other beginner readers.

Aside from the testimonies of comic authors, researchers had found two common reasons why comics were popular reading materials among children, adolescents, and adult learners. First, readers found the humor in comics interesting, which made the medium more appealing and meaningful. Second, comics had conclusions and punch lines that would build reader- anticipation, which encouraged readers to be more involved in the content of the text (Brown, 1994). A way researchers attempted to measure this appealing nature of comics was to examine and then record the amount of time it took for students to read comics. The more attractive the text was, the more time students would take to read the text. Thus, if students found the information in comics more intriguing, they would spend more time reading and problem solving the text features (Arlin \& Roth, 1978). 
Norton (2003) wanted to gain insight as to why children read the American Archie Comics. Participants included students from grades fifth through seventh, in which a little less than half of the students were identified as ELLs. The first languages of the ELLs in the study were Korean, Swedish, Mandarin, Bengali, Farsi, and Cantonese. When students had to explain why they found the comics enjoyable during interviews and questionnaires, Norton received valuable qualitative feedback. The majority of the students responded that the comics were amusing or funny, which was one of the main reasons why they liked that style of comics. In order for students to find the text humorous or amazing, one could infer that they were able to identify, translate, and understand the social and cultural witticisms and word play the author included in the language.

Humor should not be the sole reason why learners were motivated to read comics as opposed to other types of graphic media. Bruton and Marks (2004) examined and compared results from two groups of foreign language learners' perception of wants and needs about reading in the target language. Wants and needs were important variables to consider because if a learner perceived that he or she needed to read in the target language in order to accomplish academic or personal goals, the learner would be motivated to succeed. Considering perceived wants, students were more likely to complete pleasurable tasks that were attractive and even entertaining outside of the classroom if they were driven to do so. One group of students was EFL students at two selected schools in Spain, whereas the other group was a pool of American students who were learning Spanish as a foreign language. The different reading media in this study were science fiction, songs, poems, plays, comics, newspapers, magazines, brochures, advertisements, letters, forms, references, and specialists books (Bruton \& Marks, 2004). Similar to Norton's (2003) study, researchers gathered data using student comments from questionnaires.

Overall, learners in the context did not view comics as a medium they needed to read in the target language, yet a want when reading in the first language (L1) or L2. Considering the controversial history of comics in the U.S., it was surprising that the wants and needs to read comics were overall higher from the U.S. sample than the Spain sample. For example, among the EFL participants, $20 \%$ of the learners wanted to read comics in English, whereas 15\% of the learners felt a necessity to read comics in English. In regards to the EFL learners reading in their L1 (Spanish), 35\% wanted to read comics, whereas only $1 \%$ thought it was necessary to read comics in the L1. Between the American students, $50 \%$ of the students wanted to read them in Spanish, whereas 20\% felt a necessity to read them in the L2. When American students commented on reading comics in their L1 (English), $55 \%$ of the students wanted to read comics, whereas only $15 \%$ felt it necessary to read them (Bruton \& Marks, 2004). Therefore, the data presented implied that the wants to read comics tended to be higher than the necessity to read comics in the L1 and foreign language. This brings up questions of students' perception of the legitimacy of reading comics beyond the fulfillment of motivation, but to achieve language and academic needs.

Jones (2010) also analyzed EFL students' motivation to read in the target language. Motivation was measured by administering pre and post study surveys to a group of 25 first year college students at an all women's university in Japan. One of the purposes of this study was to examine the effects comics would have on participants' motivation to read in English. Participants filled out a questionnaire in their L1, in which they had to rate and justify their perception of the necessity to read in English and Japanese. The post questionnaire was given as a way to compare any changes in the students' perception and attitudes of reading in the L2 after the intense English reading program. The results from the pre-study survey yield that the majority of the students disliked and even admitted to barely reading in Japanese (Jones, 2010).

In regards to reading in English, 44\% had positive views about reading in the language. Even though they dislike reading in their L1, $96 \%$ of the participants thought reading in English was not a desire, yet a necessity. According to the post-project survey, the results showed that $84 \%$ of the participants had a positive perception of reading comics in English. Participants shared that English comics were favorable because the illustrations helped with comprehension of unknown or challenging vocabulary. Interestingly, those who had negative views about reading in English claimed these attitudes were due to lack of English vocabulary and the annoyance of constantly reverting to a dictionary (Jones, 2010). Overall, students felt propelled to continue to read other books in English because of the everlasting impressions they had from reading English comics during the project.

Another study included interviews and questionnaires from grade school students in Chicago, in which the intention was to learn more about students' general reading interests. So the extent to which students found comics popular was examined by asking students which comic books they read more often. During that time period, the results showed that more boys than girls from all grade levels read comics. More importantly, an 
average amount of students read a significantly high number of comics (Witty, 1941). Given the history of comic readership in the U.S., comics could have had a place in the educational setting, claimed the wellknown researcher and author in linguistics Stephen D. Krashen (as cited in Schwarz, 2006). Comics and graphic novels actually invigorated students to pick up a book and read, which helped promote the act of reading and developing literacy skills. Therefore, Krashen concluded that this form of graphic media could be the first step to motivate learners to build literacy skills (as cited in Schwarz, 2006).

\subsection{Vocabulary Analysis and Acquisition in Comics}

Even if a learner were highly motivated to read in the target language, would he or she not need to meet basic literacy skills to read in the language? And even though graphic novel author Jeff Smith was enthused to learn how to read from newspaper comics, he was prevented from reading them independently since the readability of the comics did not align with his academic level of development. And regardless of favorable results from students' perceived wants and needs to read comics (Jones, 2010), there were a significant percentage of students who had negative views about reading in the L2 due to their lack of vocabulary. So, questions of vocabulary acquisition and analysis of reading comics were important variables that influenced students' motivation. These variables were also vital for understanding the type of vocabulary included in the text of comics and how vocabulary could influence the academic legitimacy within this medium.

Vocabulary acquisition was one of the major factors in research that could influence a student's ability to comprehend a given text. Allan Paivio (1971) hypothesized that there were two ways a person could further acquire vocabulary: (1) verbal associations, such as target vocabulary words written or read, and (2) visual imagery, such as target vocabulary words presented as an image (p. 354-355). More specifically, Paivio's Dual Coding Theory (DCT) attempted to explain the correlation between success at learning an L2 and using illustrations. Similar to Paivio's use of the DCT to explain how comics (or visual imagery) could help students' memory of vocabulary in the language, Oller's (1983) Episode Hypothesis was used to also further explain how the story line and logic found in comics could help students retain information.

Since opposing viewpoints had arisen claiming that comics would not benefit learners with lower reading abilities, Oller (1983) was attempting to shed light on the benefits of reading comics. Similarly, when the question of whether or not comics were appropriate reading material for learners had arisen, James $\mathrm{L}$. Thomas (1983) completed a study to analyze the appropriateness of the text (based on context, language, etc.). Thomas took 20 different random comics, with three samples from each, and categorized them according to grade level. After categorizing the samples, observations of the comics showed that not the entire text was on first grade level. In fact, some comics included text that was above students' reading level, yet still included grade appropriate content. Thomas shared insight that the average and above average readers in the intermediate grades would discover that comics are easy materials to read but by reading the text alone (Thomas, 1983).

Similar to findings from Thomas' (1983) study, Liu (2004) hypothesized those students with low reading levels, yet reading a higher leveled text (Group A) would benefit the most from a comic-style text. That is, the images would increase the student's ability to recall the information read. However, Liu speculated that if high-level readers were given a low-level text (Group B), their recall abilities would not be influenced by the images in the comic-style format. Among the adult ENL learners, Lui's data displayed that students from Group A scored significantly higher than Group B. This data further explained Paivio (1971) and Oller's (1983) theories about images used to help language learners retain, recall, and comprehend information read.

In addition, American psychologist, Robert Lee Thorndike (1941), was another researcher who conducted studies to support comics and literacy. Thorndike studied the range of vocabulary difficulty level in popular comic books during that time period, like Batman and Spider-Man. First a vocabulary count was made and then small sections of the comics were analyzed for reading difficulty. Then the amount of time in which the student was reading the comic was questioned. Reflecting on observations from the vocabulary analysis, comic readers on average discovered around 100 new and unfamiliar words. In addition, comic book readers read and encountered more words than students were expected to read (Thorndike, 1941). Only a small number of words seemed to be objectionable, whereas more than $22 \%$ of the standard vocabulary used was to express colloquial meanings common in everyday informal language (Thorndike, 1941). Therefore, this study provided a vocabulary analysis, in which one could infer that students encountered and acquired more academic vocabulary than the inappropriate or even vulgar vocabulary that many had claimed before. 
Lastly, students on average read comics when they were not in the classroom and when experiencing the luxury of pleasure reading in their free time. Hence, Milton (2008) explored literature and studies that examined the effects nontraditional mediums and materials had on vocabulary acquisition amongst foreign language learners. Similar to personal reflections on the Horst and Meara (1999) study, incidental exposure of the foreign language was controlled by giving a learner a comic to read once a week, aside from classroom assignments. Then vocabulary intake was measured using the Vocabulary Knowledge Scale, which learners used to answer questions on a continuum from not knowing the word to definitely knowing the word's meaning. Since results showed a significant increase in definitely known vocabulary, Milton concluded that comic books included more lexical opportunities and images to help students retain the vocabulary compared to other mediums learners likely encountered incidentally, such as films and songs (Milton, 2008).

\subsection{Developing Multiple Literacy Skills with Comics}

There was more than just vocabulary building and analysis to consider when determining academic success from a comic curriculum. The comic reader, regardless if he or she was reading in the L1 or L2, experienced several mental processes and cognitive tasks simultaneously. Jacobs (2007) coined this experience as multimodality, which is "the increasing multiplicity and integration of significant modes of meaning-making, where the textual is also related to the visual, audio, spatial, behavioral, and so on" (p. 21). These multiple modes of meaning making typically happen while reading a comic more so than when reading the traditional non-comic style text. This was due to the multiple codes the reader needed in order to make meaning from the text, which was embedded in a unique multilayer format.

James W. Brown (1977) provided a theoretical framework in which comics could be used in foreign language classroom to build visual literacy and language. Brown highlighted how comics were made of two different types of codes: (1) linguistic codes and (2) visual codes (p. 20). He explained how French scholars used comics to teach linguistics, culture, and literature, in which these two codes were interchangeably addressed throughout curriculum. A sample exercise included transcription of the writing content in an indirect style. Students were also directed to orally read speech balloons with appropriate intonation during another exercise. To encourage higher order thinking tasks students imagined the characters' thoughts and then created dialogue for blank balloons. Culture was studied through the analysis of the linguistic and visual codes (since both codes displayed cultural differences). And finally, literature could be studied by analyzing the medium as a form of narrative. Instructors also had students compare the structure and approach found in comics and graphic novels to structures in other narrative forms (Brown, 1977).

Similar to Brown's (1977) theory about a coding system used to describe how the linguistics and visual literacy were enhanced during foreign language learning. Paivio's (1971) DCT theory also elucidated a similar coding system but as processes. DCT during top-down processing gave second language learners an additional strategy to use when problem-solving a text. This could be best exemplified when students were instructed to compose the text (i.e., dialogue or narrative) when communicating a meaningful story for a provided sequence of visuals. Morrison, Bryan, and Chilcoat (2002) noted this process in their article when studying how to create comics and the benefits for students from a comic book curriculum. When students created their own comics, they intuitively determined words that matched with the illustrations. On the other hand, DCT and bottom-up processing allowed students to organize and represent language as sensory groups, like sight, hearing, touch, taste, and smell. Thus, the second language reader would use clues from the text (such as familiar words and the context) to help him or her make connections between the senses and the print (Lui, 2004).

Like others who reacted to Wertham's (1954) views against the structure of comics and the reading abilities of comic readers, Jacobs (2007) argued that the format and structure of the images in comics required sophisticated abilities. These abilities were presented when the reader analyzed and developed meaning from the story and characters. For instance, the panels alone supported the interpretation and analysis of the story in a way that traditional texts could not do for students. Using the comic Polly and the Pirates, several text features expounded upon the foundation of visual literacy in graphic novels and comics. The features helped students understand many things about literature and how to use multimodal, yet complex literacies.

One visual feature found in the format of the comic was text boxes, which were shown like scrolls. This feature exemplified a visual code that assisted readers to understand the time period and form of medium. Similar to what Krashen (as cited in Schwarz, 2006) and Brown (1977) theorized about visual codes aiding linguistic and literary skills, Jacobs (2007) claimed that the font and punctuation was another visual feature 
found in the format of the comic. More specifically, the font and punctuation supported students' understanding of the characters' emotions, rhythm in which they spoke, and other audio elements that could help the reader mentally hear the dialogue. Jacobs (2007) further elaborated, that readers were able to hear the voice of the narrator due to the enhancement of the font in the text. Even the artistic features of the text boxes added a visual element to the auditory sensory experience of the reader.

While reading comics, students negotiated meaning and made connections. There were several reasons why comics helped students activate their multiple systems of meaning making. The layouts of comics urged students to actively and continually negotiate meaning. That is, each page consisted of multiple panels, which were divided by physical and metaphorical gutters (Jacobs, 2007). A small change in the gutter could change the meaning of the text, and therefore influence the meaning that the student interpreted and negotiated (McCloud, 1993; Eisner, 1996). Thus, readers were unconsciously forced to fill-in the blanks between panels by making connections between what the characters were saying or thinking (i.e., the dialogue within the speech or thought bubbles), objects, settings, and font, in order to comprehend the story.

\section{DISCUSSION OF THE LITERATURE}

\subsection{Strength in the Literature}

Unlike Arlin and Roth (1978), other researchers used reliable and valuable means of collecting data to understand motivation while using comics during L2 learning (Witty, 1941; Norton, 2003; Bruton \& Marks, 2004; Jones, 2010). The studies included datum compiled from interviews, surveys, and questionnaires, which gave qualitative data to explain why students found comics attractive or why students were motivated to read selections from this medium as opposed to another media. In addition to the tools used to collect qualitative data, Norton (2003) not only asked students questions about the Archie Comics but also recorded students' reactions and emotional responses during the informal interview. For example, when students were informed about parents' and teachers' perceptions about the comics, their behavior, body language, and verbal responses implied that they were defensive and even upset. Including these additional observations made the study more authentic and validated the reason why students felt as passionate to read comics. Thus, to understand why students were motivated to read a certain book, one should gather information from the students' thoughts, feelings, viewpoints, and actions, which could explain why comics were so popular.

Another strength from the literature that could also influence the validity and reliability of the data was the sample size from two studies. Even though the other studies included the average number of students to a classroom, Bitz $(2004 ;$ 2009) looked at student-written comics from a larger sample of students. Including work from a more than average sample size made the analysis of student work more valuable than work analyzed from a few works. Also, because the researchers included data from a large group of students, one could easily generalize the analysis to a greater population of students from that location (i.e., the country) or environmental environment (i.e., the school or classroom).

\subsection{Drawbacks or Limitations}

One limitation was that the Arlin and Roth (1978) study failed to collect qualitative data when gathering information about the effects of comics on student motivation. If not challenging, motivation could be an abstract variable that was difficult to measure with tools that collect numerical or statistical data. This meant that methodologies designed to collect quantitative data would not make the study reliable or valuable when determining whether or not motivation was a key factor that would influence foreign language instruction. For instance, researchers concluded that if students spent more time reading a comic, the text would be more appealing. Thus, it was challenging to determine if the researcher was using methods and tools to test variables that were intended to be tested: that is, whether researchers tested to see if a learner would continue to read a comic versus a non-comic based on the attractiveness of the text. Or were researchers trying to understand the cognitive and emotional triggers (motivation) that caused the student to not only pick the book up, but to continue reading the selection? Even though researchers collected observations once a week proving that the students were in fact reading (e.g., lip or eye movement), different instruments of data collection could had been taken into consideration to measure variables that were originally intended to be measured.

Another of the caveats in the literature was the lack of including students' goals and impressions for reading an attractive book. Students' goals for learning a second language could explain why some students were driven to develop speaking skills as opposed to reading or literacy skills. For instance, Arlin and Roth's (1978) study did not consider what the students expected to gain from reading a graphic novel (e.g., a good 
storyline, entertaining visuals, or informal character dialogue). This shortcoming raises more questions. For example, if a learner found the text and content of the story more appealing, would not he or she spend less time reading since his or her goal would be to satisfy the anticipation of what would happen next in the story? Or if a learner found the artwork, along with the text, equally appealing, would not the time spent reading the selection be lengthier, since more attention would be given to several different text or literary features instead of one?

In addition, when understanding the underlying goals students had for reading comics, Norton (2003) only highlighted one reason why students read the Archie Comics (i.e., humor). This might had been due to the fact that humor was one of the most obvious literary elements the author consistently included in the language and storyline. Focusing on one type of comic, which coincidently was a comical or entertaining magazine, could have led students to only respond that humor was a motivational factor. If the study consisted of participants who read other styles of comics, the researcher would had collected responses from a diverse comic reading population.

Another drawback was that researchers who analyzed comics only reported personal thoughts and characteristics of works under surveillance. Thomas (1983), Thorndike (1941), and Bitz (2004; 2009) included subjective results, in which an analysis was made on the appropriateness of the vocabulary, elements included in student-created comics, and reactions to published comics. These studies would have been higher in reliability and validity if a tool (e.g., a scale) was used to measure the appropriateness and difficulty of the text for students at the elementary grade level. To control for the subjectivity of the analysis, researchers could have organized a large committee of practitioners and professionals in the field to conduct an analysis of the vocabulary. By having more than one person review the vocabulary in a range of different comics, the researchers would had been controlling for potential biases, which causes the analysis to be reliable and valid.

Even though Milton's (2008) study included promising results, since students were given a reliable tool in order to analyze and question their acquisition of the vocabulary, drawbacks were still acknowledged. It was unclear if students knew how to use the tool that gave the researcher significant results. For instance, looking at the scale, a student would have had to understand exactly what the phrase "to know the word" meant (Milton, 2008). If several students in the classroom read the scale in which they thought the previously mentioned phrase meant something different than other students in the class, the results would have been skewed. Even though giving students this scale to complete while they read was efficient and ideal for the classroom setting, researchers should have included an additional procedure to test vocabulary acquisition. For instance, students could have provided an accurate sentence in which they put the word into context. In addition, instruction and practice using the scale would have been an additional procedure to ensure that every student used the tool correctly and that researchers were collecting reliable and valid data on vocabulary acquisition.

During Witty's (1941) study, the researcher wanted to determine how popular comics were by asking students which comics they read more often. However, it was unclear whether or not students were given a list of comics to choose from. If so, how many and what kind of comics were on that list? If students only chose from a list of one type of comics, then responses would only test the popularity amongst that particular type and not comics as a diverse medium. Similar to drawbacks from the Norton (2003) and Witty (1941) studies, Lui's (2004) study only highlighted the effects of one type of visual on adult L2 comprehension.

\subsection{Implications for Future Research}

Not only could future researchers study the effects that other visuals have on L2 comprehension, but also efforts could be made to study L2 retention and not solely comprehension. Even though Milton (2008) compared other visuals to comics and the effects the different mediums had on students' retention, more research is needed. Reflecting on questions about the types of comics used during the Witty (1941) and Norton (2003) studies, researchers should compare the differences between various styles of comics under the umbrella medium. In the past, the pop culture superhero comics were popular, but today comics come in different forms and styles and are written for different purposes. There are manga (Japanese influenced comics), Marvel and Dark Horse (common superhero publishers), graphic novels (longer stories told as novels with the graphic format), and newspaper comic strips (which include the humorous short clips of sequential art juxtaposed with jokes and other entertainment popular among the culture). Thus, studies that include a range of these different types of comics could give researchers, teachers, librarians, and others in the field a better idea of how motivation, vocabulary acquisition, and the development of multimodal skills are 
influenced from reading selections within this umbrella medium.

Paivio (1971) and Oller (1983) introduced two theories to justify the potential comics could have had when learners acquire new vocabulary or information (i.e., being able to notice, process, retain, and then recall the input). As a proposal for future research, it would be interesting to observe these theories using recent and innovative tools. For instance, vocabulary acquisition could be compared under different conditions like when learners are using technological software to create comics as opposed to paper and pen. Having language learners create comics using technological software (e.g., Comic Life), could influence the frequency of retention and recall rate of information and vocabulary. Technology is also a current and growing field that could bring forth other issues about multimedia learning that were not considered in past research. Even Oller's (1983) Episode Hypothesis could be tested if language learners are given systems like iMovie, to recreate a storyline of a graphic novel to improve retention in the language. DCT could also be tested, if students are instructed to include verbal narration to go along with a graphic storyline visually presented as a movie clip.

And finally, looking at the studies from the literature as a whole, there was surprisingly a lack of experimental empirical studies, compared to theoretical and observational empirical studies. Besides testing the influence comics could have on student motivation, needs, and wants, quantitative data would have been beneficial for learning more about vocabulary acquisition and the development of multimodal skills and literacies. For instance, it would be valuable to collect quantitative data when measuring cognitive behavior of comic readers compared to non-comic readers. Since many senses were activated, but at a cognitive level, collecting mental behaviors could help researchers understand how students process multimodal texts versus single-layered texts. Thus, a plea for research on the influence comics can have on learners' cognitive activity should be made, especially in fields like Cognitive Psychology, Sociology, and Educational Psychology.

\section{PRACTICAL APPLICATION FOR ENL/EFL INSTRUCTION}

\subsection{Steps for Instructors before Implementation of Comics}

The greatest challenge ENL and EFL instructors faced are determining how to incorporate effective strategies and materials that are typically used with mainstream students. For instance, Thorndike (1941) analyzed the range of vocabulary difficulty among popular comics during that time period, yet failed to keep in mind the linguistic levels of ELLs in the analysis. If given the opportunity to teach in an EFL setting again (see Context), a current analysis on graphic novels, newspaper comics, and other popular texts within this medium would be conducted. Even though there did exist leveled graphic stories (Jones, 2010), the analysis would serve as a systematic reference that organizes titles according to learners' linguistic levels, comprehension, vocabulary knowledge, visual literacy, and other confounding factors that influenced L2 readability.

In addition, there are very limited current resources for ENL instructors using comics to improve language goals for different settings, such as the ones outlined in a study by Swain in 1978. Certain researchers have gathered vital information concerning the study of language within comics, including forming schemata using images, identifying humor and metaphors, visual literacy or linguistics and noticing identity through discourse (Bramlett, 2012). However, today there are limited references that translate the implications found in studies and research on language in comics to an easily accessible classroom resource. Even though Swain's (1978) goals could be a starting point, ENL and EFL instruction would be less challenging if instructors had a classroom reference that would help them locate a book exemplifying the present progressive, WhQuestions or conditionals in English. Reflecting on the research, many theorists and researchers have already studied the readability and even highlighted literary devices found in these texts (Thorndike, 1941; Thomas, 1983; Gorman, 2003; Frey \& Fisher, 2008). Therefore, efforts should be made to accommodate not only the mainstream learner, but also the ELL who would linguistically benefit from the unique multimodality format presented in comics.

Were graphic novels and comics to become leveled according to English language goals, instructors would be able to effectively select the text that is most appropriate for students' diverse levels. Were this first step to be accomplished, instructors could consider dedicating a unit or lesson in which learners are taught the language and how to read comics. Reflecting on personal foreign language teaching and fieldwork observations, one cannot assume that all learners know how to navigate through the multilayered format of 
comics. Even though comics are popular reading materials among a population of readers, there are some learners who are only familiar with one format of comics (e.g., the horizontal strips found in newspapers) and others who have no experience in reading comics. Teaching Early Reader Comics and Graphic Novels by Katie Monnin (2011) is a good source that explains the fundamentals of comic vocabulary and how to read or create comics in a learner-friendly language. Aside from researching, creating a reference, and aligning texts with language objectives and academic goals, teaching students how to read this format would be another beneficial step to take before comic instruction commences.

\subsection{Literacy Development through Graphic Media}

Since Monnin's (2011) background was in literacy and comic instruction, her resource provided useful reading strategies that instructors could use with learners at the elementary grade levels. These strategies are also aligned with standards from the International Reading Association (IRA) and National Council of Teachers of English (NCTE). One activity that ENL instructors could incorporate into the classroom in order to accomplish language objectives was called Animated Schema (Monnin, 2011). Students are instructed to discuss, compare, and contrast a comic with an animated clip, but while referring to a main topic introduced before the lesson. Since many language learners organize newly acquired vocabulary, images, symbols, and ideas into thematic systems or schemas (McCloud, 1993; Bramlett, 2012), this activity would build useful reading and comprehension skills.

And finally, another resource an ENL instructor could use in the classroom is a source titled Super-Powered Word Study by James B. Carter and Erika A. Evensen (2011). When using comics during my EFL instruction in a public school on the coast of Ecuador, I lacked a lot of background literature and practical resources that could motivate and help my students progress in the language. If this source were available during my experience abroad, I would have had a better idea of how to incorporate different discoveries in research about using comics with learners. For instance, this text details sequential art, narratives, Paivio's (1971) Dual Coding Theory (DCT), word study, and vocabulary acquisition (Carter \& Evensen, 2011). Like other word study and vocabulary acquisition activities, the author provides a cutout lateral folded flashcard, which includes the character, context sentence, question, word sort, comic excerpt, and assessment. Since the image of the character associated with the target word part is included, the learner can form a mental schema and use the image of the character as a visual symbol to remember the meaning of the target word part.

Finally, looking back on the 7-12 fieldwork observations in The Bronx, English Language Arts instruction could have been stronger were students to have completed a study on the medium and authors. Using The Comic Book Curriculum by James Rourke (2010), language instructors could have built students' background knowledge and engaged them in identifying the themes and literary devices associated with superheroes. Later students could have studied the medium and create their own comic, similar to the research and work of Bitz $(2004,2009)$. However, were students to research the authors of graphic novels and even read the work of other comic authors in their class, they might have develop strong and meaningful author-to-author connections. More specifically, ENL learners would have had the opportunity to appreciate this form of popular text and potentially develop an understanding of the necessary processes and multimodal skills of comic authors.

\section{CONCLUSIONS}

It is not surprising that today this field lacks an abundance of resources that instructors need in order to effectively implement comics into the classroom. Looking back on the historical turmoil about controversial views on students reading comics, even during leisure time, one could only expect a teacher to request a student to select a preferred chapter book over a well- known graphic novel. The opposing viewpoints from historical figures and the casual rejections from instructors today, sheds light on the controversy in answering the question if comics are in fact effective materials for teaching ELLs? Better yet, researchers are challenged to question if language learners even find comics a legitimate resource to use when achieving needs and wants in the target language.

Review of the literature not only detailed how this medium could be motivational for ELLs, but also how students who read within the graphic medium were exposed to greater vocabulary and therefore improved literacy skills. Others have studied students' behaviors while reading comics, the level of readability and difficulty within the vocabulary, and theories that infer how students benefit from the multimodal and 
multilayered format. Even though the research may include limitations, such as the insufficient amount of quantitative data or the lack of inferences from objective methodologies, further research is necessary in order to understand the influence comics can have on learners' academic success. This further research will challenge the historical controversy and even the current biases of students reading comics. Overall, when practitioners become knowledgeable about the potential this medium can have on language instruction, comic resources and research-based practices would potentially be available for instructors to effectively implement with language learners.

\section{REFERENCE LIST}

Arlin, M. \& Roth, G. (1978). Pupils' use of time while reading comics and books. American Educational

Research Journal, 15 (2).

Bitz, M. (2004). The comic book project: The lives of urban youth. Art Education, 57 (2).

Bitz, M. (2009). Manga high: Literacy, identity, and coming of age in an urban high school. Massachusetts: Harvard Education Press.

Bramlett, F. (Ed.). (2012). Linguistics and the study of comics. New York: Palgrave Macmillan.

Brown, J. W. (1977). Comics in the foreign language classroom: Pedagogical perspectives. Foreign Language Annals, 10.

Brown, H. D. (1994). Teaching by principles: An inter- active approach to language pedagogy. New Jersey: Prentice Hall Regents.

Bruton, A. \& Marks, E. A. (2004). Reading texts in instructed L1 and FL reading: Student perceptions and actual selections. Hispania, 87 (4).

Carter, J. B. \& Evensen, E. A. (2011). Super-powered word study: Teaching words and word parts through comics. Florida: Maupin House.

Deasy, R. (Ed.). (2002). Critical links: Learning in the arts and student academic and social development. Washington, DC: Arts Education Partnership.

Eisner, W. (1996). Graphic storytelling and visual narrative. Florida: Poorhouse Press.

Fiske, E. (Ed.). (1999). Champions for change: The impact of the arts on learning. Washington, DC: Arts Education Partnership.

Frey, N., \& Fisher, D. (Eds.). (2008). Teaching visual literacy: Using comic books, graphic novels, anime, cartoons, and more to develop comprehension and thinking skills. California: Corwin Press.

Glasgow, J. N. (2002). Radical change in young adult literature informs the multigenre paper. The English Journal, $92(2)$.

Gorman, M. (2003). Getting graphic: Using graphic novels to promote literacy with preteens and teens. Ohio: Linworth Publishing, Inc.

Horst, M. \& Meara, P. (1999). Test of a model for predicting second language lexical growth through reading. The Canadian Modern Language Review/La Revue canadiennne des langues vivantes 56 (2).

Jacobs, D. (2007). More than words: Comics as a means of teaching multiple literacies. The English Journal, 96 (3).

Jones, E. (2010). The use of comic books style reading material in an EFL extensive reading program: A look at the changes in attitude and motivation to read in English in a Japanese university. Language Education in Asia, 1 (1).

Liu, J. (2004). Effects of comic strips on L2 learners' reading comprehension. TESOL Quarterly, 38 (2).

McCloud, S. (1993). Understanding comics: The invisible art. New York: HarperPerennial.

Milton, J. (2008). Vocabulary uptake from informal learning tasks. The Language Learning Journal, 36 (2).

Monnin, K. (2011). Teaching early reader comics and graphic novels. Florida: Maupin House.

Morrison, T., Bryan, G., \& Chilcoat, G. (2002). Using student-generated comic books in the classroom. 
Journal of Adolescent \& Adult Literacy, 45 (8).

Norton, B. (2003). The motivating power of comic books: Insights from Archie comic readers. The Reading Teacher, 57 (2).

Oller, J. W. (1983). Story writing principles and ESL teaching. TESOL Quarterly, 17 (1).

Paivio, A. (1971). Imagery and verbal processes. New York: Holt, Rinehart \& Winston.

Rourke, J. (2010). The comic book curriculum: Using comics to enhance learning and life. California: Libraries Unlimited.

Samuels, S. J. (1967). Attentional processes in reading: The effect of pictures on the acquisition of reading responses. Journal of Educational Psychology, 58.

Schwarz, G. (2006). Expanding literacies through graphic novels. The English Journal, 95 (3).

Singer, H., Samuels, S. J., \& Spiroff, J. (1974). The effect of pictures and contextual conditions on learning responses to printed words. Reading Research Quarterly, 4.

Swain, E. H. (1978). Using comic books to teach reading and language arts. Journal of Reading, 12.

Thomas, J. L. (1983). Cartoons and comics in the classroom: A reference for teachers and librarians. Colorado: Libraries Unlimited, Inc.

Thorndike, R. L. (1941). Words and the comics. Journal of Experimental Education, 10.

Wertham, F. (1954). Seduction of the innocent. New York: Rinehart \& Co., Inc.

Witty, P. (1941). Children's interest in reading the comics. Journal of Experimental Education, 10 (2). 